\title{
Building Healthcare 4.0 with Smart Workforce
}

\author{
Dr. Pushpendu Rakshit ${ }^{1}$, Ravindra Sharma ${ }^{2}$ \\ ${ }^{1}$ Assistant Professor, ABSM, Amity University, Maharashtra, India. \\ ${ }^{2}$ Assistant Professor, Swami Rama Himalayan University, Dehradun, India \\ I pushpendu_rakshit@yahoo.com, ${ }^{2}$ ravindrasharma97@gmail.com
}

\begin{abstract}
Role of Indian pharmaceutical industry has been significant over the years. It's a leading nation for catering pharma and healthcare services across globe. The development, production, distribution and appropriate utilization of medicines, as well as the supportive functions of regulation, operational research, and training, all require the involvement of competent pharmaceutical professionals. Smart workforce can always contribute for better functioning of healthcare system in a country like India. Adoption of smart technologies by human resource could represent a new competitive advantage for pharma companies exhibiting smart pharma. The dynamicconsolidation, globalization, methodical developments, public policy, and competition-have pushed human resource leaders into new territory to address dynamic needs of pharma business. There exists a digital revamp in life sciences industries even following self-reliant India mission. This is a conceptual explorative research demonstrates future of smart Indian pharma, which is in a verge to become self-reliant. This study helps to focus on pharma workforce challenges such as performance management, compensation management, motivation, promotion, talent management, training and development with the help of AMO model comprising three main components such as ability, motivation, and opportunity. This would also alert both the clinical manufacturers and users resulting in designing personalized based better future of Indian pharma industry. This is an explorative study driven by secondary sources and tends to design prototype. Future Pharma would see the business link paraphernalia across development and dispersal by using better, more reliable larger volumes of data to revolutionize manufacturing.
\end{abstract}

Index Terms-Smart human resource, digital innovations, healthcare, AMO model, Make in India.

\section{INTRODUCTION}

$\mathrm{S}$ KILLED workforce is indeed an integral part of any system to avail the competitive advantages of the contemporary market. Indian healthcare has been one of the major stakeholders in both to meet the global demand and supply and in research and developments. Pharmaceutical 4.0 as a smart factory mentions to the novel tools and procedures that are allowing smart, decentralized manufacture, with intelligent workshops, cohesive IT systems, internet of things, artificial intelligence for flexible, highly integrated and robotic manufacturing arrangements. Also, life science engineering is one of the well flourishing areas in India and post COVID-19 there exist a great scope for further enhancements. Role of patient and medical data does play a critical role and thus a protruding feature for the life science engineering for a large extensive spell. There must be a paradigm shift in this sector to generate never earlier seen ex- cellence and trustworthiness values. As per the research of Gallup, only $32 \%$ of reliant workforces sense a wisdom of belonging in their workplace. There is increasing consideration between the leaders and decision-makers apropos Pharmaceutical 4.0. Pharma industry face a chronic need to endure competitive in a market where product ranges are diversified, innovative start-ups stimulating the status-quo, logistical allies fetching more cohesive and patients more intricated in decisions around their upkeep. Realizing the potentials of gear shift would be the market differentiator for industries contending in this new normal atmosphere. This chapter tries to corelate boosting of Pharmaceutical 4.0, requiring configuration of branding scopes, potential opportunities, understandings future growth and culmination of technology with the medicinal industries principles. Population and employment are major concerns in our nation but on the contrary the skilled masses could prove to be a major game changer if skilled well (Sharma et al. 2018). There must be proper awareness and trainings to impart education in masses and make them handy so they can earn livelihood. India's biotechnology segment which encompasses biopharma, bio-industries, bio-service/s, bio-agricultural practices and bioinformatics is expected to upsurge with an average growth of 30\% annually and reach \$USD 100 million by the year 2025. Any which ways biopharma which includes vaccines, therapies and diagnostics, is the largest subset with closely $62 \%$ of total revenue at INR 12,600 crore. There have been research and developments to control the cost of lifesaving generic drugs and medicines. Also, there are many researches currently going on for finding COVID-19 vaccination. Initially there were only countable laboratories for such research and currents that surpasses in thousands. All these are possible only with dedicated and reliable workforce.

\section{REVIEW OF LITERATURE}

This draws our attention towards the needs of further research as there exists a research gap. This is an explorative research. Mentioning the major aims, this study used qualitative method on secondary sources to proceed with development of prototype. The conclusive analysis helps to build a model based on the review of literature from existing work from multiple sources and researches.

(Tomervik 1995) explores that there exist cross cultural barriers but one can overcome same. This may differ from place to place and time to time and majorly there exist cross 
cultural benefits at workplaces (Cassell 2001). Thomas (1995) explains that workforce diversities does not mean that there would be complete disagreement for the procedure of doing things but widens the scope to explore more potentials. Cox (2001) says that there exists diversification in workforce based on gender, religion and race but in healthcare sector there stands humanity as supremacy and nothing else than that as powerful. Workforce diversities can be beneficial for organizations and specially the pharma sector tends to serve all irrespective to their origins. (Saji, 2004). Effective talent retention strategies are vital for sustainable organizational growth (Sharma et al., 2019)

Performance and productivity could improve with diversified creative amalgamation of thought processes (Milliken $\&$ Martins, 1996). Performance management in group task could lead to better results (Hoffman, 1959). Pharmaceutical industry is one of the emerging industry managing and controlling manpower is a great challenge in this industry Rana et al. (2017)

Zemke, Raines, and Filipczak (2004) defined four specific generations that existing the workplace today: the Veterans, who are adaptive (aka Matures or Silent); the Baby Boomers, who are idealistic (Boomers); the Gen Xers, who are reactive (aka Xers; Hagevik, 1999); and the Nexters (aka Millennials), who are civic-minded. Veterans were born between 1922 and 1946. Each organization in pharma sector tends to compete among based on skilled workforce and taskforce (Carrel et al., 2000). (Allen et al., 2004) skilled and trained workforce could thrive for competitive advantage because different viewpoints can facilitate unique and creative approaches to problem-solving, thereby increasing creativity and innovation, which in turn leads to better organizational performance. Specially this was demonstrated during the pandemic crisis as all countries started supporting each other to meet demand and supply of pharma needs. Cloud-based human capital management solutions, insightbased analytics and democratized dashboards will enable the professionals to create a learning, collaborative and interactive talent scape for agile organization (Rana and Sharma, 2019)

The National Skill Development Corporation (NDSC), which is a not-for-profit nodal agency for skill development $\&$ entrepreneurship (Skill India Initiative) under current ministry of finance, Government of India has reported a major skill deficit in human resources for Indian pharmaceutical industry until 2022 (Er. Mandeep Singh, 2020). Branded generic medicines, low price levels, local market players driven by intense competition are key factors (McKinsey, 2020). India ranks tenth globally in terms of value, it is ranked third in volumes.

\section{OBJECTIVES}

1. To explore best workforce practices by Indian pharma industries.

2. To understand AMO model in context to Indian pharma workforce.

\section{AMO MODEL}

This model helps to critically justify employee's ability, motivation, and opportunity to participate (AMO) which in return would increase employees' affective commitment. In the following study we are demonstrating the correlation between humans, as a vital resource for organizations, not only have a decisive role in the evolution of firms, but also act as the leader of all other resources to conquer rivals in today's dynamic atmosphere of businesses. Playing a pivotal role in triumph of the firms, human resource management needs human resource systems, policies and best practices. With respect to the ability, staffing challenges, training as well as development challenges, and talent management challenges were the three themes identified. Regarding the motivation, the deficiency of compensation packages, inefficient performance management, and promotion challenges were emphasized by the participants. Communication as well as information sharing challenges and insufficient attention to empowerment factors are major concerns. Fundamental roles of a human resource practitioners must be such that they are ready to support the workplace by maintaining the sanctity of work culture(Rana, and Sahrma.,2017).. Thus, this would support in scalability and sustainability of the pharma business and would also help to have best of the employees in the organization. In addition to the mentioned themes, some miscellaneous challenges were recognized, including the imperfective HRM governance, the organizational culture obstacles, and the nature of the industry. Human resource managers must recognize efforts and thus have 360 degree of appraisal practices to support AMO of employees.

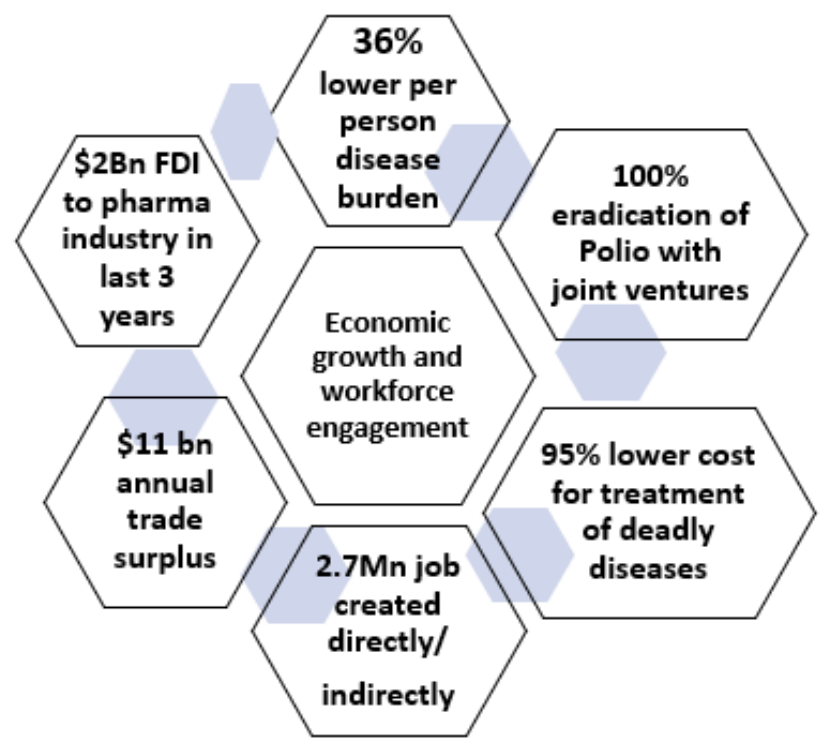

Fig.1 Economic growth and workforce engagement Source: Authors own 


\section{Major Aspects Driving AtTEntion TOWARds UPSKILLING PHARMA WORKFORCE}

Top-down approach: the transformational journey with in a pharma company commences from top management and then flows to the lower level management and the best practices flow in the living blood of organization.

R\&D: To reduce the 'time to market' for new drugs, pharma companies in India are leveraging workforce capabilities in medical skills and IT capability - a critical combination in today's research teams in global clinical R\&D for clinical trials, data management, testing, etc.

Best industrial policy practices: As most of export in our nation incorporates medicines and generic drugs thus proper export -import policies must be framed and practiced to maintain integrity of business.

Innovations: Pharmaceutical innovation must be a neverending journey and we demonstrated similar in the current pandemic crisis where the whole world is not only combating the virus but also in a way to explore the vaccination as soon as possible. Laboratories with latest tools and gadgets are equipped to provide better results.

Advancement in technology: Mechanization, automation, and computerization need people with the requisite skills to operate them. Pharma organizations must train their employees in the areas of evolving technical skills and technology-advancements from time to time.

Quality control: Increase in skill efficiency usually results in an increase in quantity, quality and output. A trained worker gives improved performance, machine and materials are carefully handled and more economically used.

\section{DISCUSSION}

India supported many nations globally through supply of medicines. By end of year 2020, most medications would have pricings based upon the outcomes they deliver, human body acceptance they show. Since numerous factors stimulus pharma manufacturing and usability results this means that there must be a paradigm shift to healthcare supervision paradigm, together to preserve the worth of all its throughputs along with sidestep challenges by the naive market entrants. If the challenge exist then still innovations would help to face the same for existing marketers. There might be situations to produce ground breaking naive drugs / medications / vaccinations for which current administrating cabinet of country, authorities and investors could support the inventions creating market values with export facilities.

Thus, would support building the associations and clinical set-ups essential to uplift not only experimentations / inventions but also in value creation. These practices would imbibe collaborations among global leaders not only in terms of technological amalgamation but also increase reachability of medicinal support.

Indian pharma companies so far have been on toes and fully feared up for combat with COVID-19 crisis. Being a larger producer of generic drugs and even a larger supplier, it is a tough rivalry of China. During the days of pandemic,

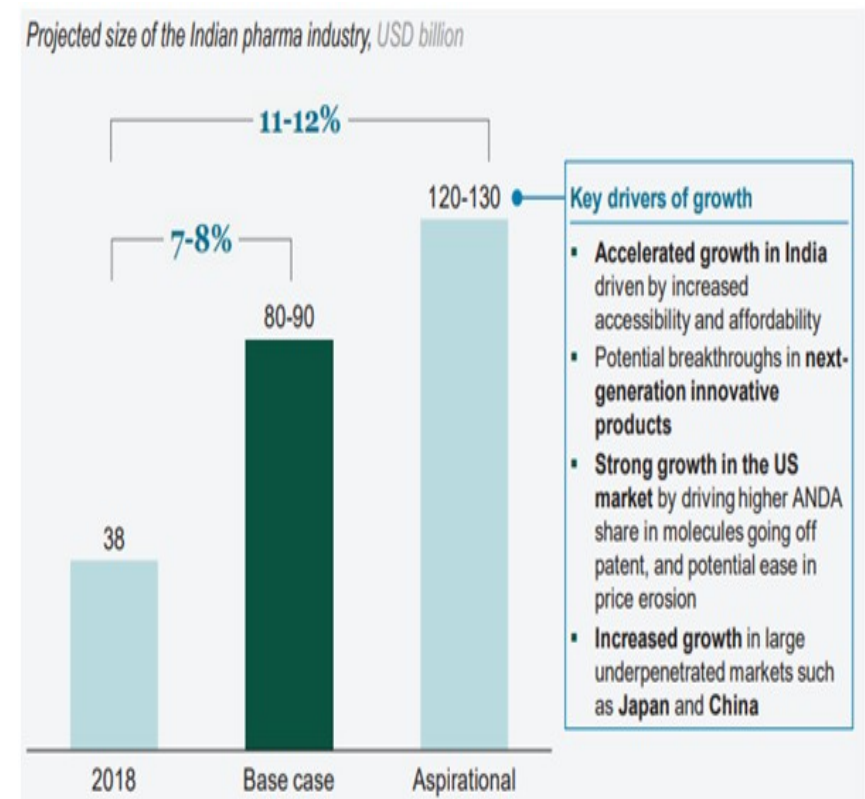

Fig.2 Indian pharma industry could grow to USD 120-130 billion by 2030

Source: IQVIA, AIOCD, Pharmexcil, IPA Team analysis, secondary research

India supplied drugs and medicines across world. Also lifted ban on exporting few of the drugs and generic medicines to tackle the crisis scenario across the countries of the world. Made in India medicines also found supporting the mantra of self-reliant India. India have been so far highly dependent on imports from China, nearly $70 \%$ in over the years for health care manufacturing. Antibiotics and several medicines related to cardiac ailments, high sugar, diabetes and tuberculosis are listed in the National List of Essential Medicines (NLEM) were available from China, thus dependency rate of other nations was very high. Now post COVID-19 scenario seems to change and new dawn of innovations and inventions have geared up across world. There seems to a be a larger scope for the nation to stand tall during this pandemic era. India have been extending continuous support to supply medicines to the nations in need. India also was appraised by World Health Organization during this crisis epoch.

\section{IMPLICATIONS}

The study offers key implications for the top and middle level managers willing to adopt best industrial practices to have competitive advantages of market. Adoption of technology and industrial practices based on technology would help to explore better results. Development of soft skills, interpersonal, problem solving, negotiation skills and best ethical practices are the key to success in modern pharma industries. Thus, the role of workforce from medical staff, manufactures, service providers, medical fraternity till entire supply chain must be adoptive to best trends in practice. 


\section{CONCLUSION}

Worldwide pharmaceutical marketplaces exist in the mid of foremost disjointedness. While evolution in advanced marketplaces will shrink, evolving marketplaces will become progressively imperative in the approaching spans. This contemporary pandemic has made world come to stand still with clinical / medicinal challenges. The world must learn a lesson from this and try to be proactive in healthcare and hygiene aspects which found absent in major parts of nations. The Indian pharma marketplace, laterally with the marketplaces of China, Brazil and Russia, would forefront developments within these marketplaces. Market in Indian has diverse features branding it as an exclusive business podium. Initially, branded generics control, manufacturing up for 70 to $80 \%$ of the retail marketplace. Next, local companies have relished a leading place determined by formulation development competences and initial investments. Then, price echelons are low, determined by strong competition. While India ranks tenth globally in terms of value, it is ranked third in volumes. These characteristics mentioned in the first portion of chapter presents their own prospects and challenges. Pricing controls and an economic sluggishness can dissuade away reserves and pointedly dampen the market, permitting it to reach only USD 35 billion by 2020 .

\section{REFERENCES:}

[1] Burmeister, C.; Lüttgens, D.; Piller, F.T. Business model innovation for Industrie 4.0: Why the "Industrial Internet" mandates a new perspective on innovation. Die Unternehmung 2016, 70, 124-152

[2] Cassell, C. 2001. Managing diversity., Contemporary human resource management. In T. Redman \& A. Wilkinson (Eds.) (pp. 404-431). Harlow: Pearson Education.

[3] Cox, T. 2001. The Multicultural Organization. Academy of Management Executive, 5:24-27.

[4] Er. Mandeep Singh, Lack of adequate skilled workforce plagues Indian pharma,2016.

[5] Gross, J.; Wangenheim, F.V. The Big Four of Influencer Marketing. A Typology of Influencers. Mark. Rev. St. Gallen 2018, 2, 30-38.
[6] Hofmann, E.; Rüsch, M. Industry 4.0 and the current status as well as future prospects on logistics. Comput. Ind. 2017, 89, 23-34.

[7] Kotler, P.; de Bes, F.T. Inovativní Marketing: Jak Kreativním Myšlením Vitězit u Zákazníkŭ; Grada Publishing a.s.: Prague, Czech Republic, 2005.

[8] Rana G., Sharma R., Goel A.K. (2019) Unraveling the Power of Talent Analytics: Implications for Enhancing Business Performance. In: Rajagopal, Behl R. (eds) Business Governance and Society. Palgrave Macmillan, Cham.

[9] Rana, G. and Sharma, R. (2019), "Emerging human resource management practices in Industry 4.0", Strategic HR Review, Vol. 18 No. 4, pp. 176-181. https://doi.org/10.1108/SHR-012019-0003.

[10] Rana, G., Sharma, R., Rana, S. (2017). The Use of Management Control Systems in the Pharmaceutical Industry. International Journal of Engineering Technology, Management and Applied Sciences. Volume 5, Issue 6, 1223.

[11] Rana, G., Sharma, R. (2017). Organizational Culture as a Moderator of the Human Capital Creation-Effectiveness. Global HRM Review, 7(5), 31-37.

[12] McFeely, S and Pendell, R. What Workplace Leaders Can Learn from the Real Gig Economy. Gallup. 2018. Available online

at https://www.gallup.com/workplace/240929/workplaceleaders-learn-real-gig-economy.aspx.

[13] McKinsey \& Company, Inc. India Pharma 2020 Propelling access and acceptance, realizing true potential, Pharmaceutical and Medical Products Practice, 2020.

[14] Sharma R., Singh S.P., Rana G. (2019) Employer Branding Analytics and Retention Strategies for Sustainable Growth of Organizations. In: Chahal H., Jyoti J., Wirtz J. (eds) Understanding the Role of Business Analytics. Springer, Singapore. https://doi.org/10.1007/978-981-13-1334-9_10.

[15] Sharma, R., Jain, V., Singha, S. P. (2018). The Impact of Employer Branding on Organizational commitment in Indian IT Sector. Journal of Business and Management.20 (1), 4954.

[16] Tomervik, K. 1995. Workforce diversity in Fortune 500 corporations headquartered in Minnesota: Concepts and practices. Academy of Human Resource Development (AHRD) Conference Proceedings, St. Louis, MO.

[17] Thomas Jr., R.R. 1995. A Diversity Framework. In Martin M. Chemers. et at. Diversity in Organizations, SAGE Publications, 1995. 